\title{
Performance Requirements on Remodeling Apartment Housing and TOPSIS Evaluation
}

\author{
Jaeho Cho and Jaeyoul Chun \\ Department of Architectural Engineering, Dankook University, 126 Jukjeon-dong, Yongin-si, Gyeonggi-do 448-701, Republic of Korea \\ Correspondence should be addressed to Jaeyoul Chun; jaeyoul@dankook.ac.kr
}

Received 8 April 2015; Accepted 18 May 2015

Academic Editor: Jurgita Antucheviciene

Copyright (C) 2015 J. Cho and J. Chun. This is an open access article distributed under the Creative Commons Attribution License, which permits unrestricted use, distribution, and reproduction in any medium, provided the original work is properly cited.

\begin{abstract}
Functional improvement needed in remodeling projects is determined by users in a complex manner since remodeling projects require performance improvement against deterioration. This study defines fundamental Remodeling Performance Criteria (RPC) for apartment housing by referring to performance criteria of both domestic and international performance-related systems. In this case study, performance evaluation of Construction Element Method (CEM) for remodeling projects was conducted based on RPC. For the objective evaluation of CEM, performance scores were calculated and normalized by using the Technique for Order of Preference by Similarity to Ideal Solution (TOPSIS) model, which is used in a multicriteria decision-making method. The TOPSIS evaluation model allows for a comprehensive and comparative analysis on the performance of the remodeling solution. The TOPSIS model in this study suggests a standard logic of performance evaluation for aged buildings as it analyzes the degree of deterioration at the prior remodeling phase and predicts the performance improvement level for CEM at the remodeling planning phase.
\end{abstract}

\section{Introduction}

Recently, as the domestic housing supply rate is reaching over $100 \%$ nationally, demand for remodeling related to functional improvement has been increasing due to the deterioration of existing apartment housing which was built earlier [1]. Regardless of whether new construction or remodeling is carried out, the users' requirements are determined with functional improvement in a specific manner.

The international standardization of building performance is currently in progress and is being led by the International Organization for Standardization (ISO).

In Japan, a study has been conducted to establish both the Evaluation Index of Performance (EIP) of building elements and an accreditation system for remodeling housing components [2].

Users' requests should be clearly defined since they are continually made and changed in all phases of a building life cycle, including planning, design, construction, maintenance, and destruction phases [3]. Therefore, a review of housing performance should be conducted according to the users' criteria, which are physical, psychological, physiological, and so forth [4].
In Korea, despite the availability of a design guide for housing performance that has been recommended by the Ministry of Land, Transport and Maritime Affairs, it has not been effectively utilized for the evaluation of CEM.

In the case of remodeling projects, in particular, studies on the performance evaluation of building elements have not been sufficiently performed. The study of EIP should be carried out as a priority in order to facilitate the continuous development of construction techniques in remodeling and to induce the extension of a building life cycle.

Constructability in remodeling projects is regarded as an important criterion for performance evaluation due to the structural constraints of remodeling. Constructability can be defined as the degree of ease in the measurement of the degree of difficulty for construction works [5]. Construction methods for remodeling are classified according to techniques for addition, component relocation, additional installation, exchange, layout change, and scale change [6]. Constructability is evaluated in order to select the most effective method through the comprehensive measurement of safety, environmental feasibility, and economic feasibility in the construction phases. 


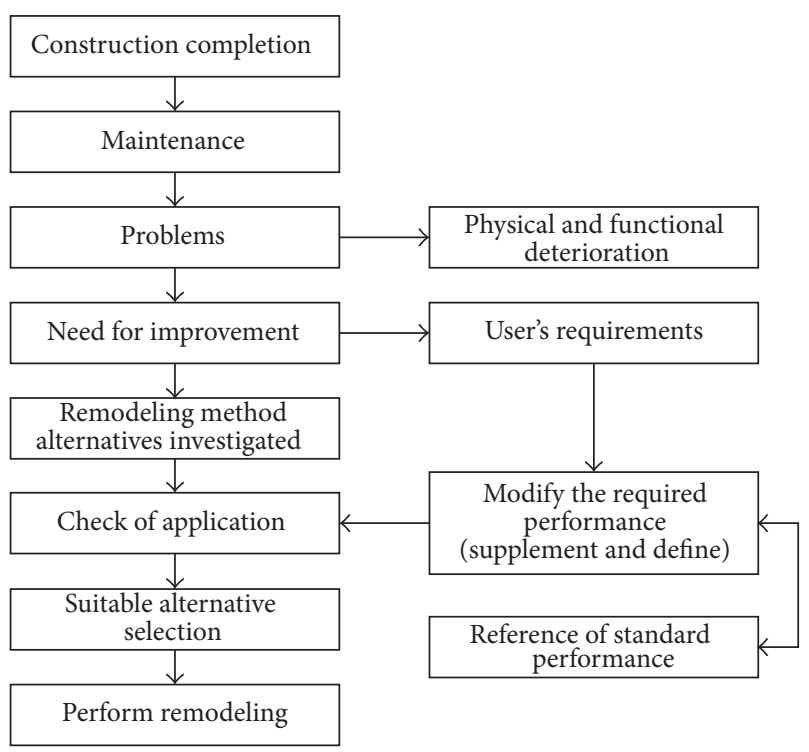

Figure 1: Remodeling procedures.

The basic procedures for remodeling projects are shown in Figure 1.

In this study, the fundamental criterion for the performance evaluation of domestic apartment housing is redetermined to ensure successful quality in remodeling projects.

Furthermore, an evaluation method of CEM is proposed by using the Technique for Order of Preference by Similarity to Ideal Solution (TOPSIS) model, which is a multicriteria decision-making method based on various attributes. TOPSIS is continuously redefined and extended so that it handles multiple extreme criteria (PIS: positive ideal solution; NIS: negative ideal solution), by which a decision maker can provide more than one pair of extreme points [7]. The Ordered Weighted Averaging (OWA) operator was suggested to solve the problem of multiple extreme criteria in TOPSIS [7].

The standardized score of the performance evaluation using TOPSIS can be effectively utilized in comparative analysis between different design solutions. In addition, extreme criteria PIS and NIS in TOPSIS are well coped with multicriteria decision related problems in construction performance evaluation. Many other kinds of methods in a multicriteria decision analysis (MCDA) or a multiattribute utility theory (MAUT) require complex ways: they usually combine other theories, such as fuzzy environment, analytic hierarchy process (AHP), and OWA. These approaches have limitations when applied in industrial engineering. The TOPSIS model will be an extremely simple method in performance evaluation in this study. A performance property in CEM must have only one pair of extreme criteria points. CEM has multiple performances that can be classified into one pair of extreme criteria by generating the other performance item. Figure 2 below presents a concept diagram regarding 1:1 relationship between function and performance for CEM evaluation.

Therefore, the TOPSIS evaluation model can be easily used as a user's decision-making tool because it analyzes the degree of deterioration and measures the performance improvement level for remodeling CEM. The performance definition in this study was cited from a master's thesis [1].

\section{Methods and Scopes}

The original purpose of building structures is regarded as being achieved when the performance of a certain construction method is sufficiently obtained compared to the performance criteria of certain elements of building structures.

The contents of this study are described in the following procedures for quality evaluation of CEM for remodeling:

(1) Existing studies on the definition of performance criteria and quality evaluation of CEM were investigated.

(2) Problems found in CEM evaluation for remodeling were analyzed.

(3) Various items of performance criteria were determined through the analysis of international and domestic systems related to housing performance and the requirements were reorganized to match the domestic status of remodeling the apartment housing.

(4) An EIP for each requirement was set to the relevant regulations.

(5) An evaluation method for remodeling constructability was proposed, considering the concept of constructability used in new construction works.

(6) The feasibility of this study was proposed through case analysis.

\section{Literature Review}

Studies on the performance criteria of apartment housing have been continuously conducted since the late 1990s and the "Study on Development of Performance Grade Indication System for Remodeling of Deteriorated Apartment Housing [8]" was recently conducted. In addition, studies on the quality evaluation of product performance are being conducted in various fields of Architecture, Engineering, and Construction (AEC). The findings obtained through the investigation of the existing studies are described by dividing them into "the definition of performance criteria" and "the method of quality evaluation of CEM."

3.1. Studies on the Definition of Performance Criteria. Housing Research Institute (HRI) has conducted numerous studies related to housing performance including the "Analysis and Prevention Countermeasure for Major Defect of Apartment Houses [9]," "Performance Guideline for Dry Construction Type-Heating Panel System of Apartment Houses [10]," "The Establishment of the Thermal Performance Standard of Exterior Windows in the Extended Balcony [11]," and "Customizing Remodeling Items for Deterioration Apartment Houses [12].”

The Ministry of Construction \& Transportation published "Checklist of Design Criteria of Building Structures in Consideration of Remodeling [13]" and "Safety Inspection Manual for Housing Reconstruction Projects (2003).” In regard to green energy saving policies, the Ministry of Land, 


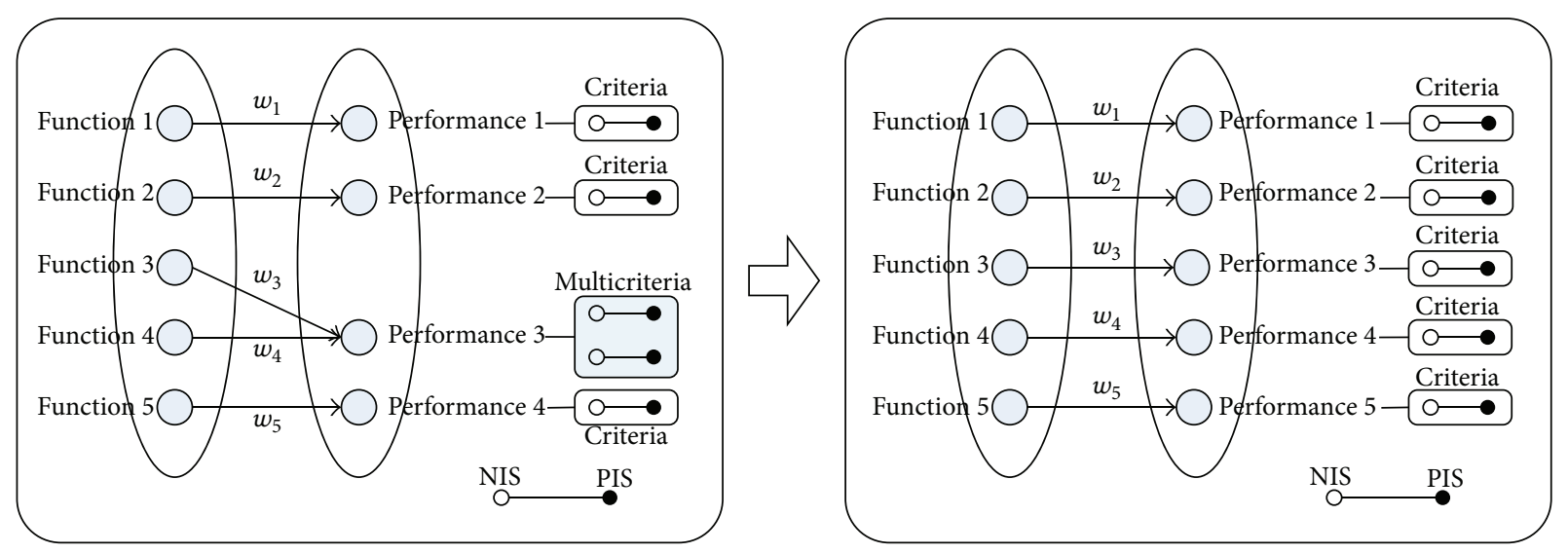

FIGURE 2: 1:1 relationship of function and performance with unique extreme criteria for CEM evaluation.

Transport and Maritime Affairs has been gradually reinforcing the performance criteria with the introduction of energy saving design criteria for building structures since 2009.

Korea Institute of Construction Technology (KICT) conducted the studies entitled "Study on Apartment Housing Performance Grade Indication System [4]," "Development of Performance Insurance System in Construction New Technology [14]," "Study on Strategy for Development of Apartment Housing Performance Grade Indication System [15]," "Study on Establishment of Guideline for Construction of General Building Structures (RC Structures) Preparing for Remodeling," and "Study on Development of Performance Grade Indication System for Remodeling of Deteriorated Apartment Housing [8].”

In addition, a study provided an acoustic performance for life in apartments [16]. All these studies have proposed the physical criteria required for housing performance evaluation and expanded enough to include the coping strategies like the warranty for defects in apartment housing.

3.2. Researches on the Evaluation of Element Technique. Researches were made on a multicriteria decision-making method in Value Engineering (VE) evaluation using the TOPSIS model [17]. A study was performed for quality evaluation on design solutions based on performance criteria by utilizing House of Quality (HOQ) technique of Quality Function Deployment (QFD) [18].

Singhaputtangkul et al. proposed a QFD-based knowledge management system for building envelopes [19]. Li et al. suggested another QFD-based knowledge management system combining itself with a fuzzy-TOPSIS that is used in a multicriteria decision-making method [20].

Despite the sustained studies on QFD till present, the focus of the reviews on its literatures has been made on the difficulties in the utilization of QFD in quality plans and benchmarking [21]. One of the findings is that the majority, up to $80 \%$, of the methodological difficulties are related to the stage of elaborating quality matrix such as "interpreting the customer's voice" [22]. Another finding is that reducing the methodological difficulties in developing the quality matrix is a key factor in encouraging and expanding the use of QFD [21].
A study was conducted to see quality evaluation by using the AHP technique as a MCDA method to select appropriate building exterior materials [23]. Lee and Chun [24] utilized a FDD/IWDM method for the evaluation of alternatives. A feature of the FDD/IWDM method is to evaluate the relative priorities of multirequirement functions. Lee and Chun [25, 26] also focused on the design change and proposed a quantitative assessment method for alternative designs from the perspectives of cost, performance, and constructability. Cho [27] evaluated technologies to ensure green performance of apartment houses. Lee et al. [28] evaluated constructability items in terms of limitations to improve in the insulation performance on remodeling projects. Yin et al. proposed a decision support framework for building renovation strategies [29]. Yau suggested a multicriteria decision-making method for homeowners' participation in building maintenance [30]. Zhang and Lei studied environmental multiassessment for renovating residential buildings [31], adopting the principles of environmental efficiency in proposing an assessment framework for existing residential buildings that simultaneously reflects functionality and sustainability. The study demonstrated that the proposed framework provided useful information for prioritizing critical renovation issues, leading to notable improvements in functionality and sustainability.

Due to the word limit in this study, many other further studies on MCDA have been omitted.

\section{Problems in Evaluation System for CEM}

In order to evaluate the performance of CEM, the users' required functions should be systematically determined. The performance is related to the functions, performance targeting, and an evaluation scale.

Designers and engineers can easily obtain the title, adoption field, adopted building elements, the major effects of CEM, and the characteristics of CEM from the summaries of the technique information. The basic specifications to see the performance of CEM can be given by including representative plans or images in the introduction information. However, it does not present the suitable outcomes as the evaluation of the CEM about the adoption into building elements based on the Requirement Performance Criteria 


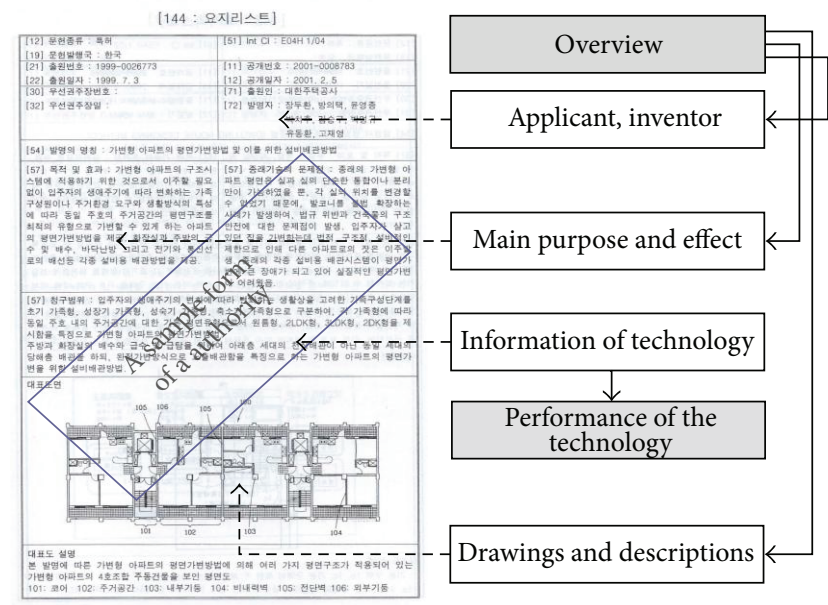

FIGURE 3: Composition of a CEM summary list.

(RPC). Even though information on the original performance of CEM has been additionally proven, the information usually includes the experimental evaluation obtained from an on-site test.

The objective evaluation of CEM and the comparison of performance between different construction element techniques are extremely difficult since the current performance evaluation system is not required to use any standard performance grade. Moreover, items for the evaluation of constructability are not specifically proposed in CEM evaluation.

Figure 3 presents a case of CEM information on the remodeling of a domestic building structure proposed by a certification institute.

\section{TOPSIS}

The Value Engineering (VE) technique is generally used in the manufacturing industry as a method of determining the ways to realize the function more economically by reviewing the function of materials systematically. In the VE technique, the total score for the function is calculated by using a weighted value and the evaluation grade of the function.

The TOPSIS technique, used as a multicriteria decisionmaking method, is able to analyze a preference by considering the positive ideal solution and negative ideal solution simultaneously. The TOPSIS method was originally proposed by Hwang and Yoon [32] to identify solutions from a finite set of alternatives. The detailed traditional TOPSIS solution can be found in Li et al. [20].

The VE technique evaluates the quality based on both the evaluation of each item for multiple functions and the total summed scores for a product evaluation. On the other hand, the TOPSIS method analyzes the product preference by considering the multiple properties of a product. Currently, a preference refers to the score obtained from the quality evaluation of a product and its ranges are distributed between 0 and 1 . The quality is assumed to improve as the preference score approaches closer to 1 .

Although both the VE technique and the TOPSIS method allow quality comparison amongst multiple alternatives, their evaluation methods differ. The VE technique generally specifies 3 or 5 grades for the evaluation of function while the TOPSIS method performs evaluation based on the distance after setting a positive ideal solution and a negative ideal solution. For the TOPSIS evaluation, the product quality value is divided by the total distance scale and then normalized in the ranges between 0 and 1 . Hence, the value score calculated by the distance based the TOPSIS model can be generally used for making a decision in the AEC industry.

The preference value of TOPSIS allows comparison evaluation to be made among multiple alternatives and can be reused by many users as knowledge-based information.

In the TOPSIS evaluation model, the weighted value of the performance property is determined by the user. The performance property defines the evaluation criteria based on the positive ideal solution (PIS) and the negative ideal solution (NIS). Every single performance property must possess a PIS and a NIS; these two criteria neither contradict nor conflict with each other in terms of function description. In other words, every performance property has one PIS and one NIS, respectively. Therefore, the TOPSIS evaluation model will result in an objective evaluation on CEM purely due to performance measurement.

The procedures of TOPSIS can be expressed in the following steps.

Step 1. Calculate the normalized decision matrix. The normalized value $n_{i j}$ is calculated as

$$
n_{i j}=\frac{x_{i j}}{\max \left(x_{i j}\right)} \quad(i=1, \ldots, m j=1, \ldots, n) .
$$

In this study, the value $n_{i j}$ was normalized to the absolute values rather than the relative values of the TOPSIS model.

Step 2. Calculate the weighted normalized decision matrix. The weight $w_{j}$ is defined by a 10 -point scale priority:

$$
v_{i j}=w_{j} n_{i j} \quad(i=1, \ldots, m j=1, \ldots, n),
$$

where $w_{j}$ is the weight of the $i$ th criterion.

The total sum of $w_{j}$ in the original TOPSIS theory is 1. However, a user's subjective decision is always in priority involved for performance in all cases; thus, the user weighting definition is required to be as simple as possible. Extensive numbers of methodology and researches on the weighting approach have been conducted. Calculation of the weight is out of the range of this study. The 10-point scale priority is applied for the TOPSIS weight in this study in order to allow a reflection of a user's intuitive decision.

Step 3. Define the positive ideal solution (PIS) and negative ideal solution (NIS) as

$$
\begin{aligned}
& A^{+}\left\{V_{1}^{+}, \ldots, V_{n}^{+}\right\}, \\
& A^{-}\left\{V_{1}^{-}, \ldots, V_{n}^{-}\right\},
\end{aligned}
$$

where, for benefit criterion, 


$$
\begin{aligned}
& v_{j}^{+}=\max _{i}\left\{v_{i j}\right\}, \quad j=1,2, \ldots, n, \\
& v_{j}^{-}=\min _{i}\left\{v_{i j}\right\}, \quad j=1,2, \ldots, n,
\end{aligned}
$$

and, for cost criterion,

$$
\begin{aligned}
& v_{j}^{-}=\max _{i}\left\{v_{i j}\right\}, \quad j=1,2, \ldots, n, \\
& v_{j}^{+}=\min _{i}\left\{v_{i j}\right\}, \quad j=1,2, \ldots, n .
\end{aligned}
$$

Step 4. Calculate the distances of each alternative from both PIS and NIS using the following equations, respectively:

$$
\begin{array}{ll}
d_{i}^{+}=\sum_{j=1}^{n} \operatorname{dis}\left(v_{i j}-v_{j}^{+}\right), & i=1, \ldots, m, \\
d_{i}^{-}=\sum_{j=1}^{n} \operatorname{dis}\left(v_{i j}-v_{j}^{-}\right), & i=1, \ldots, m,
\end{array}
$$

where $\operatorname{dis}\left(v_{i j}-v_{j}^{+}\right)$is the distance between the rating of alternative $i$ and PIS on the $j$ th criterion and $\operatorname{dis}\left(v_{i j}-v_{j}^{-}\right)$is the distance between the rating of alternative $i$ and NIS on the jth criterion.

Step 5. Calculate the relative closeness to the ideal solution. The relative closeness of alternative $A_{i}$ with respect to $A^{+}$is defined as

$$
R_{i}=\frac{d_{i}^{-}}{d_{i}^{+}+d_{i}^{-}}, \quad i=1, \ldots, m .
$$

According to the relative closeness degree $R_{i}$, the ranking order of all alternatives can be determined. Any alternative with the highest $R_{i}$ is the most desirable alternative.

In this study, $R_{i}$ values from the TOPSIS model are in the ranges between 0 and 1; the solution is classified as a higher performance as $R_{i}$ values approach closer to 1 .

\section{Analysis of Performance Requirements}

In this section, the original performance of CEM for remodeling is defined by analyzing the domestic and international performance evaluation systems to improve the performance of the building structures.

6.1. Analysis of the Domestic Performance Evaluation System. The domestic Housing Performance Grading Indication System was introduced in the 2005 Housing Act in order to provide accurate information for consumers and improve the quality of housing. This system has been made compulsory for apartment housing with 1,000 or more households since 2008; it includes items comprising 20 categories that belong to 5 sections, including noise, structure, energy environment, living environment, and firefighting. The Housing Performance Grading Indication System helps consumers to choose the housing type with the desired performance when planning or purchasing, since the system provides easy indication of housing performance together with standard grades and performance values.
6.2. Analysis on the International Performance Evaluation System. Housing Quality Indicator (HQI) of United Kingdom as an index used for evaluation of housing quality was designed to evaluate the quality of housing by assigning scores for characteristics of not only inside the housing but also outside the housing. The original purpose of the HQI evaluation system was to evaluate the quality of new construction apartment housing. However, it has been used for evaluation of housing quality with extensive ranges intending for public/private deteriorated housing of which revision was done.

HQI is composed of 10 indices including approximately 340 detailed Evaluation Indices of Performance (EIP) of quality in 3 major items including location, design, and performance. Furthermore, it is unique that the IPE can be adjusted to satisfy new environment or various social requirements with those 340 detailed HQI indices.

The Housing Performance Grading Indication System in Japan was designed based on the "Housing Quality Secure Facilitation Law." This system aims to promote the organization to systematically seek for the solutions for defect disputes related to housing and to support the market conditions that help consumers to safely purchase their houses. The primary content of the system is about a 10-year compulsory term to guarantee against the housing defects. Housing performance evaluation items are composed of 9 subcategories with 28 detailed items.

Quality Association (Association Qualitel) is a public service cooperation established by the Minister of Housing of the French government in 1974. The Qualitel Label System which was initiated in 1986 provides users with the outcomes of performance evaluation of building structures. At the time of its establishment, it aimed for the evaluation of design in new construction housing. The Qualitel Label is composed of 7 evaluation items and determines whether the design holds certain labels of quality [33]. In each item, the scores from 1 to 5 are given and the Qualitel Label is assigned when the score is 3 or more for all items.

6.3. Analysis Outcomes. Requirement performance criteria must be first defined in order to exchange and to repair building elements to achieve a certain level of housing performance. This is because an environment enables the user to select the appropriate CEM with the standard performance.

As a result of the comparison on the domestic and international performance evaluation systems, many similarities between the items were observed in terms of performance subjects, such as (1) durability and safety, (2) habitability and sanitation, (3) maintainability, (4) eco-friendliness, (5) energy saving, (6) aesthetic aspects, and (7) consideration for elderly people. However, the domestic performance evaluation system was shown to be insufficient in the detailed evaluation for the consideration of elderly people, crime prevention, energy saving, and aesthetic aspects compared to those of the international performance evaluation system. Therefore, the performance items of remodeling that would cope with the domestic system were defined by referring to the items of the international performance evaluation in Table 1 . 


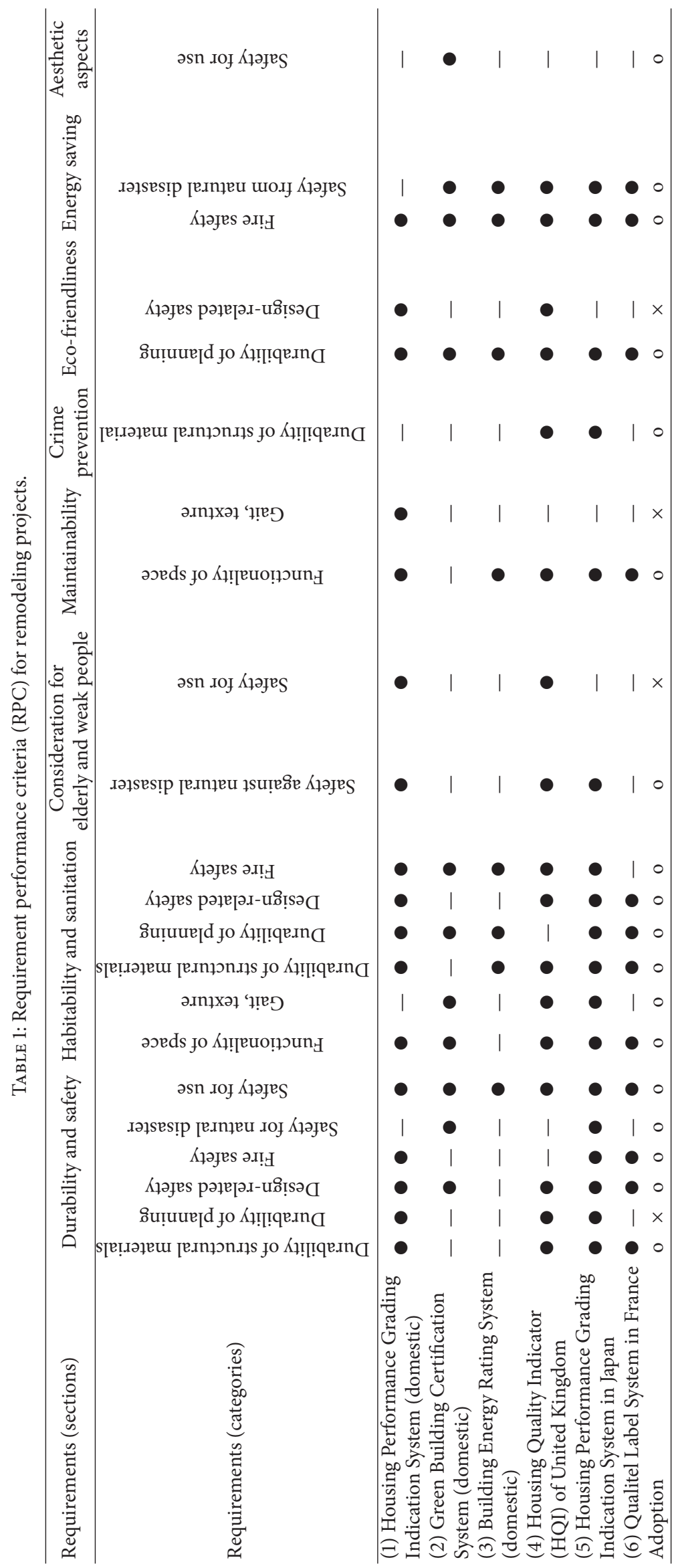


TABLE 2: Evaluation index of performance for remodeling and PIS/NIS.

\begin{tabular}{|c|c|c|c|c|}
\hline \multirow{2}{*}{ Sections } & \multirow{2}{*}{ Number } & \multirow{2}{*}{ Items } & \multicolumn{2}{|c|}{ Evaluation Index } \\
\hline & & & $\mathrm{T} / \mathrm{F}$ & Grade \\
\hline \multirow{14}{*}{ Durability and safety } & 1.1 & Maintenance/repair of initial performance & $\bullet$ & \\
\hline & 1.2 & Extension of structural life & & Gr. 3 \\
\hline & 1.3 & Improvement in seismic performance & • & \\
\hline & 1.4 & Improvement in bending or deformation performance & • & \\
\hline & 1.5 & Improvement in collapse and destruction prevention & - & \\
\hline & 1.6 & Improvement in impact resistance performance & $\bullet$ & \\
\hline & 1.7 & Improvement in local compressive load performance & $\bullet$ & \\
\hline & 1.8 & Improvement in load resistance performance & $\bullet$ & \\
\hline & 1.9 & Improvement in distribution pressure resistance & - & \\
\hline & 1.10 & Improvement in fire detection and alert performance & & Gr. 3 \\
\hline & 1.11 & Improvement in smoke control and evacuation & & Gr. 3 \\
\hline & 1.12 & Improvement in fireproof and noncombustion & & Gr. 3 \\
\hline & 1.13 & Improvement in safety against natural disasters & $\bullet$ & \\
\hline & 1.14 & Prevention against slip, collapse, and fall & - & \\
\hline \multirow{17}{*}{ Habitability and sanitation } & 2.1 & Expansion and secure area & $\bullet$ & \\
\hline & 2.2 & Secure ceiling height & $\bullet$ & \\
\hline & 2.3 & Impact absorption, noise-proof & & Gr. 3 \\
\hline & 2.4 & Secure view & & Gr. 3 \\
\hline & 2.5 & Secure natural lighting & & Gr. 4 \\
\hline & 2.6 & Improvement in artificial lighting & & Gr. 3 \\
\hline & 2.7 & Prevention for visual fatigue and secure visibility & $\bullet$ & \\
\hline & 2.8 & Improvement in noise absorbing performance & ○ & \\
\hline & 2.9 & Improvement in light weighted impact sound-proof & & Gr. 4 \\
\hline & 2.10 & Improvement in heavy weighted impact sound-proof & & Gr. 4 \\
\hline & 2.11 & Improvement in bathroom noise-proof performance & & Gr. 4 \\
\hline & 2.12 & Improvement in boundary noise-proof performance & & Gr. 3 \\
\hline & 2.13 & Reduction in self-noise occurrence & $\bullet$ & \\
\hline & 2.14 & Improvement in thermal insulating performance & & Gr. 3 \\
\hline & 2.15 & Improvement in dew-proof performance & $\bullet$ & \\
\hline & 2.16 & Reduction in release of interior hazardous air pollutant & & Gr. 3 \\
\hline & 2.17 & Improvement in ventilating and wind flowing & & Gr. 3 \\
\hline \multirow{3}{*}{ Consideration for the weak } & 3.1 & Consideration for people with visual impairment & $\bullet$ & \\
\hline & 3.2 & Consideration for people with hearing disabilities & $\bullet$ & \\
\hline & 3.3 & Consideration for the handicapped and the weak & $\bullet$ & \\
\hline \multirow{5}{*}{ Maintainability } & 4.1 & Reinforcement of fouling resistance & $\bullet$ & \\
\hline & 4.2 & Variability of space planning (plane) & & Gr. 4 \\
\hline & 4.3 & Facility variability & • & \\
\hline & 4.4 & Easiness of conservation and repair & & Gr. 4 \\
\hline & 4.5 & Easiness of replacement and repair & • & \\
\hline \multirow{2}{*}{ Crime prevention } & 5.1 & Performance of trespassing prevention & $\bullet$ & \\
\hline & 5.2 & Reinforcement of surveillance function & - & \\
\hline \multirow{4}{*}{ Eco-friendliness } & 6.1 & Recyclability, renewability, and reusability of wastes at destruction & $\bullet$ & \\
\hline & 6.2 & Prevention for air pollution while handling wasted materials & $\bullet$ & \\
\hline & 6.3 & Prevention for soil pollution while handling wasted materials & $\bullet$ & \\
\hline & 6.4 & Prevention for water pollution while handling wasted materials & $\bullet$ & \\
\hline \multirow{6}{*}{ Energy conservation } & 7.1 & Utilization of natural energy & 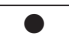 & \\
\hline & 7.2 & Improvement in thermal insulation & & Gr. 3 \\
\hline & 7.3 & Improvement in air tightness & & Gr. 3 \\
\hline & 7.4 & Improvement in performance and function of facility & & Gr. 3 \\
\hline & 7.5 & Improvement in facility efficiency (energy and water) & & Gr. 3 \\
\hline & 7.6 & Extension of facility life & & Gr. 3 \\
\hline \multirow{5}{*}{ Aesthetics } & 8.1 & Improvement in aesthetics for indoor common area & $\bullet$ & \\
\hline & 8.2 & Improvement in aesthetics for indoor private area & $\bullet$ & \\
\hline & 8.3 & Improvement in external wall aesthetics & $\bullet$ & \\
\hline & 8.4 & Improvement in rooftop aesthetics & - & \\
\hline & 8.5 & Improvement in outdoor aesthetics & - & \\
\hline
\end{tabular}


TABle 3: Constructability evaluation index for remodeling and PIS/NIS.

\begin{tabular}{|c|c|c|c|c|}
\hline \multirow{2}{*}{ Performance sections } & \multirow{2}{*}{ Number } & \multirow{2}{*}{ Categories and items } & \multicolumn{2}{|c|}{ Evaluation index } \\
\hline & & & $\mathrm{T} / \mathrm{F}$ & Grade \\
\hline \multirow{10}{*}{$\begin{array}{l}\text { Constructability } \\
\text { (manufacturability-workability) }\end{array}$} & 9.1 & Duration of design (unit: days) & & Gr. 3 \\
\hline & 9.2 & Duration of the initiation of manufacturing (unit: days) & & Gr. 3 \\
\hline & 9.3 & Duration per construction unit (unit: days) & & Gr. 3 \\
\hline & 9.4 & Demanding crews (unit: crews/unit) & & Gr. 3 \\
\hline & 9.5 & Demanding hypothesis per construction unit (hypothesis/unit) & & Gr. 3 \\
\hline & 9.6 & Quality safety (reliability) & • & \\
\hline & 9.7 & Easiness of clamping to and removal from existing elements & • & \\
\hline & 9.8 & Level of difficulty for curing & & Gr. 3 \\
\hline & 9.9 & Workability and capacity for fine-tuning at work site & • & \\
\hline & 9.10 & Work compatibility & $\bullet$ & \\
\hline \multirow{2}{*}{ Work safety } & 10.1 & Safety for construction work & & Gr. 3 \\
\hline & 10.2 & Safety for maintenance & & Gr. 3 \\
\hline \multirow{2}{*}{ Energy conservation } & 11.1 & Energy consumption at production stage & & Gr. 3 \\
\hline & 11.2 & Water consumption at production stage & & Gr. 3 \\
\hline \multirow{3}{*}{ Eco-friendliness } & 12.1 & Release of hazardous volatile substances & & Gr. 3 \\
\hline & 12.2 & Dust at production stage & & Gr. 3 \\
\hline & 12.3 & Noise at production stage & & Gr. 3 \\
\hline
\end{tabular}

\section{Evaluation Index of Performance (EIP)}

In this section, detailed requirements and the Evaluation Index of Performance (EIP) will be established based on the defined performance items for remodeling that were proposed in Section 6. EIP is equivalent to the existing performance criteria used for newly constructed buildings. It is used to ensure the performance prior to remodeling as well as the performance after remodeling. Users can confirm and compare the degree of improvement in performance achieved in the subject building structures by using EIP.

EIP is applied differently for each CEM according to the characteristics regarding the diverse levels of the performance including durability, variability, noise protection function, solar protection, fire protection, and firefighting. EIP measurements are categorized either by criteria grading or by certain performance presence. In case of grading the criteria, grading is assigned according to the grades from 3 to 5. In case of the binary type, two types are assigned as true (value: 1) or false (value: 0). A grading scale is applied to the TOPSIS model after standardization in the ranges between 0 and 1 since the RPC is not standardized in the same scale.

Table 2 shows a list of detailed requirements and EIP for remodeling. The contents of EIP are carefully described in the study performed by Lee [1] and the study entitled "Study on Development of Performance Grade Indication System for Remodeling of Deteriorated Apartment Housing" by KICT [8].

Constructability is considered in order to minimize the issues that may occur in the construction phases such as economic feasibility, safety, environmental feasibility, and space-workability. In this study, the Evaluation Index for Constructability (EIC) was established by combining the constructability items that are generally applied for new construction work, which is shown in Table 3. The details of EIC are described in the study performed by Lee [1].

\section{Case Analysis}

Remodeling is composed of "nonchangeable elements" and "improvable elements." Nonchangeable elements which include a floor-to-ceiling height limit and a core position because the majority of apartment housing have wall type structure. Some examples of improvable elements are replacement of sanitary pipelines, change of shaft layout, change of access doors, and so forth. In this case study, design alternatives which are to be improved are selected in consideration of the remodeling constraints when new pipelines are installed in an aged bathroom space. The degree of performance improvement will be measured using the TOPSIS model by comparing respective design solutions before and after remodeling of the aged bathroom.

The shaft layout prior to the remodeling had a structure constraint that did not allow regular inspection. The structure is subjected to change in order to allow regular inspection with reshaping of the shaft. In the existing deteriorated space in the apartment housing, a noise occurs since a sewage pipeline is installed in the ceiling where the down surface of the floor of the upstairs household is. Getting a sewage pipeline buried in the bathroom floor with the additional $80 \mathrm{~mm}$ thick flooring is planned as the first alternative method for troubleshooting. For the second alternative method, the noise will be completely blocked by getting both sewage and waste water pipelines buried in a noise-proof wall.

The status prior to the remodeling, summary of the applied CEM, and performance evaluation of the applied CEM were reorganized by referring to EIP for remodeling, which are shown in Tables 4 and 5. Figure 4 presents the 


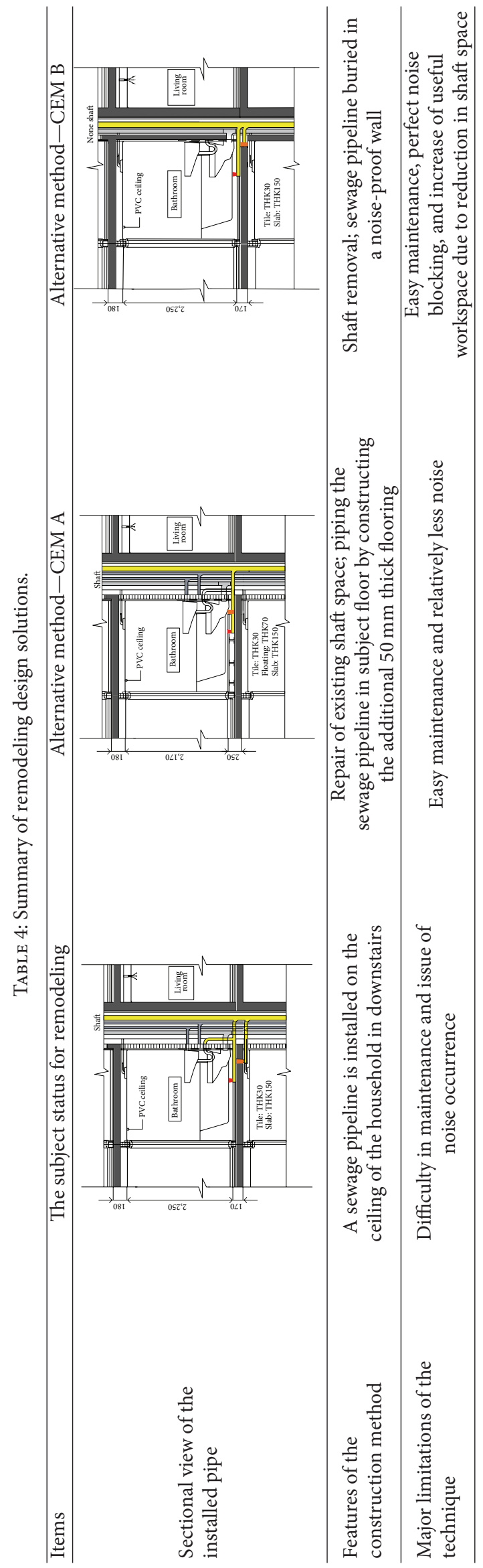


TABLE 5: Performance evaluation of the design solutions.

\begin{tabular}{|c|c|c|c|c|c|c|c|}
\hline \multirow[b]{2}{*}{ Item } & \multirow[b]{2}{*}{ Weighting } & \multicolumn{3}{|c|}{ Evaluation standard performance } & \multicolumn{3}{|c|}{ Weighted standard performance } \\
\hline & & $\begin{array}{c}\text { Deteriorated } \\
\text { status }\end{array}$ & $\begin{array}{c}\text { Alternative } \\
\text { method-A }\end{array}$ & $\begin{array}{c}\text { Alternative } \\
\text { method-B }\end{array}$ & $\begin{array}{c}\text { Deteriorated } \\
\text { status }\end{array}$ & $\begin{array}{c}\text { Alternative } \\
\text { method-A }\end{array}$ & $\begin{array}{c}\text { Alternative } \\
\text { method-B }\end{array}$ \\
\hline 2.01 & 10 & $\mathbf{0}$ & $\mathbf{0}$ & 1 & 0.00 & 0.00 & 10.00 \\
\hline 2.02 & 10 & 1 & 1 & 3 & 3.33 & 3.33 & 10.00 \\
\hline 2.08 & 10 & 0 & 1 & 1 & 0.00 & 10.00 & 10.00 \\
\hline 2.11 & 10 & 0 & 2 & 4 & 0.00 & 5.00 & 10.00 \\
\hline 2.16 & 9 & 0 & 3 & 3 & 0.00 & 9.00 & 9.00 \\
\hline 4.01 & 9 & 0 & 1 & 1 & 0.00 & 9.00 & 9.00 \\
\hline 4.03 & 7 & 1 & 1 & 0 & 0.00 & 7.00 & 7.00 \\
\hline 4.05 & 7 & 0 & 1 & 1 & 0.00 & 7.00 & 7.00 \\
\hline 6.01 & 4 & 0 & 1 & 1 & 0.00 & 4.00 & 0.00 \\
\hline 6.02 & 4 & 0 & 1 & 0 & 0.00 & 4.00 & 0.00 \\
\hline 6.03 & 4 & 0 & 1 & 0 & 0.00 & 4.00 & 0.00 \\
\hline 6.04 & 4 & 0 & 1 & 0 & 0.00 & 4.00 & 0.00 \\
\hline 7.04 & 7 & 0 & 1 & 1 & 0.00 & 7.00 & 7.00 \\
\hline 7.06 & 7 & 0 & 2 & 3 & 0.00 & 4.67 & 7.00 \\
\hline 8.02 & 10 & 0 & 1 & 1 & 0.00 & 10.00 & 10.00 \\
\hline 9.03 & 10 & - & 2 & 3 & - & 6.67 & 10.00 \\
\hline 9.04 & 10 & - & 2 & 3 & - & 6.67 & 10.00 \\
\hline 9.06 & 10 & - & 1 & 1 & - & 10.00 & 10.00 \\
\hline 9.07 & 8 & - & 0 & 1 & - & 0.00 & 8.00 \\
\hline 9.09 & 8 & - & 0 & 1 & - & 0.00 & 8.00 \\
\hline 10.01 & 10 & - & 2 & 3 & - & 6.67 & 10.00 \\
\hline 11.01 & 10 & - & 2 & 1 & - & 6.67 & 3.33 \\
\hline 12.01 & 10 & - & 1 & 3 & - & 3.33 & 10.00 \\
\hline
\end{tabular}

analyzed data obtained from the performance evaluation on the applied TOPSIS model.

In the case study, the performance improvement before remodeling and after the application of the CEM was analyzed for the bathroom space. The weight of EIP was defined by the user's subjective needs. The weight is different in all projects in terms of user's requirements. In the case study, 10point scale priority was applied. The weight was obtained by 3 users in average since performance evaluation differs by user's determination on the weight.

EIP (2.01) and EIP (4.03) have the same performance property with each different function description. However, these outcomes of EIP have different extreme criteria (PIS: true; NIS: false). Alternatives A and B show the contradicting performance evaluation score by the different criteria.

The composite performance of alternative A was analyzed as 0.79 and that of alternative B was analyzed as 0.83 . In terms of constructability, the performance of alternative A and that of alternative B were evaluated as 0.53 and 0.91 , respectively. Alternative B was excellent in both the required performance and the constructability compared to those of alternative A. In future study, total composite value of performance improvement will be possibly calculated if the performance before and after remodeling is compared in one housing project.

\section{Conclusions}

Both personal- and national-wide interests in the housing remodeling rather than in the new construction are increasing as a trend. This study selected fundamental RPC for remodeling through research investigation on housing performance for new housing construction in domestic and international housing construction markets. With the increasing demand for remodeling, performance evaluation that is related to functional improvement is expected to facilitate successful management of design and product development. This case study contributes to TOPSIS utilization as a standard method for the performance evaluation on aged apartment housing. Major conclusions of this study are summarized as follows:

(1) Required performance for remodeling of apartment houses was categorized as 8 sections with 56 detailed items. For constructability, 4 sections with 17 detailed items were presented. For the establishment of EIP, domestic related criteria were referred to.

(2) The TOPSIS method was used to measure the performance improvement degree on remodeling design solutions before and after remodeling and to present composite performance scores with multiperformance properties, including constructability. 

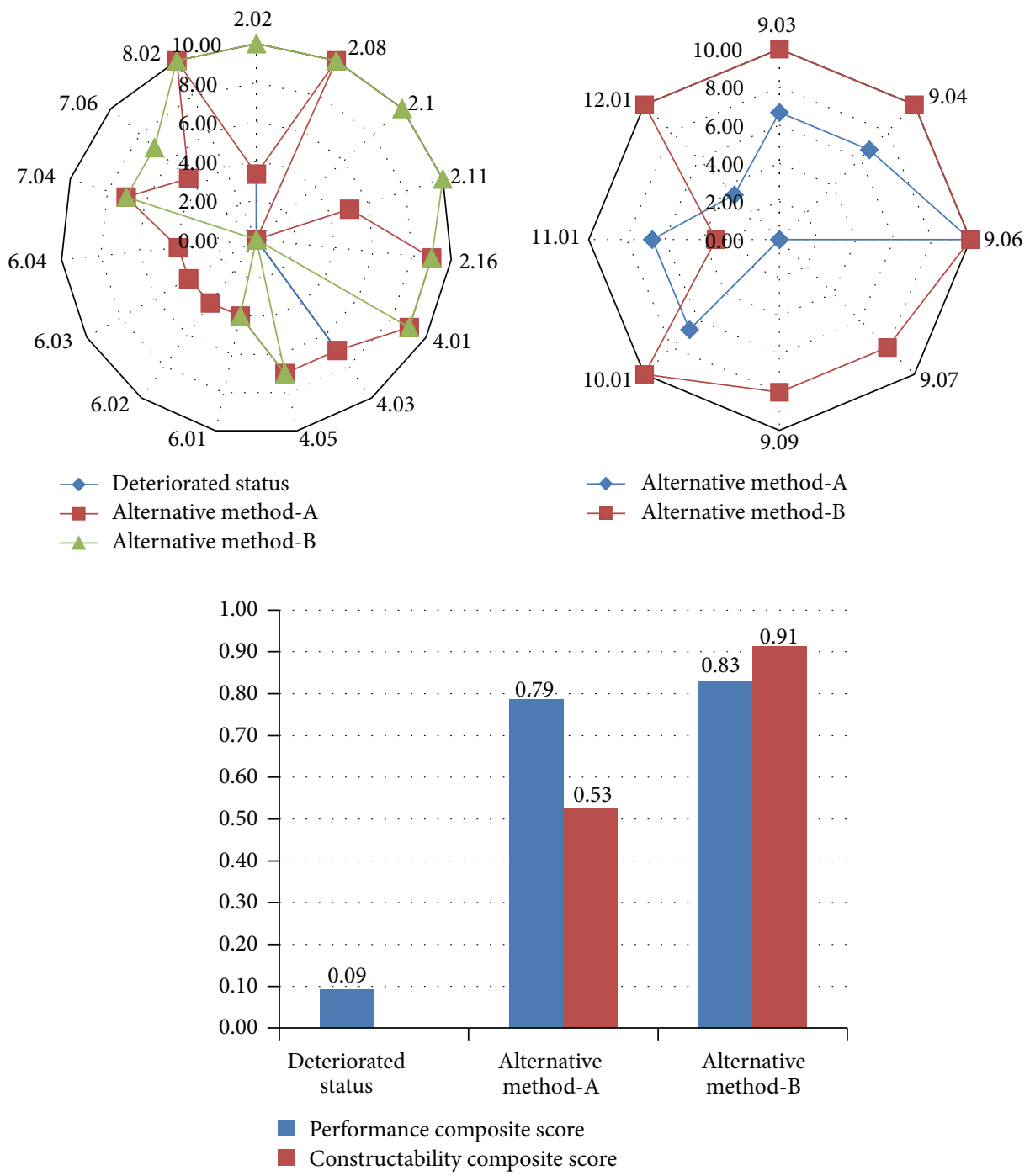

FIGURE 4: TOPSIS evaluation on performance and constructability for each alternative.

(3) PIS and NIS of the TOPSIS method provided objective performance evaluation scores for CEM by defining a unique performance property that can be related to one or more function requirements.

(4) Users' environment of remodeling projects was considered in the TOPSIS evaluation since it allowed the users to decide the weight for performance.

(5) Research on standardization of remodeling EIP is required since EIP varies by each research institution.

For future study, it is recommended to make an elaborated survey on the industrial utilization and verification of users' objectivity evaluation through the comparison with the existing performance evaluation methods such as VE and QFD.

\section{Conflict of Interests}

The authors declare that there is no conflict of interests regarding the publication of this paper.

\section{Acknowledgment}

This research was supported by the National Research Foundation of Korea (NRF) (no. NRF-2012R1A1A2043186).

\section{References}

[1] Y. H. Lee, A study on evaluation system of elemental techniques for remodeling building [M.S. thesis], Dankook University, 2009.

[2] Housing Performance Evaluation and Certification Association, 2009, http://www.hyoukakyoukai.or.jp/seido/info.html.

[3] S. Isaac and R. Navon, "Feasibility study of an automated tool for identifying the implications of changes in construction projects," Journal of Construction Engineering and Management, vol. 134, no. 2, pp. 139-145, 2008.

[4] KICT, "Study on apartment housing performance grade indication system," KICT Report, 2005.

[5] W. C. Cha, B. W. Lim, C. H. Shin, B. H. Shin, J. S. Lee, and J. Y. Chun, "Availability evaluation system for remodeling of existing apartment houses," Korea Journal of Construction Engineering and Management, vol. 9, no. 5, pp. 204-213, 2008. 
[6] Korean Intellectual Property Office (KIPO), "Remodeling technology of building structures," Technology Trends Survey Report, 2004.

[7] Y. Chen, K. W. Li, and S.-F. Liu, "An OWA-TOPSIS method for multiple criteria decision analysis," Expert Systems with Applications, vol. 38, no. 5, pp. 5205-5211, 2011.

[8] KICT, "Study on development of performance grade indication system for remodeling of deteriorated apartment housing," KICT Report, 2013.

[9] S. B. Lee, J. S. Ko, H. W. Paeng, and J. H. Oh, "Analysis and prevention countermeasure for major defect of apartment houses," House Research Institute, vol. 71, pp. 144-158, 2001.

[10] D. H. Lee, M. H. Cheon, and J. M. Choei, "Performance Guideline for Dry Construction Type-Heating Panel System of Apartment Houses," House Research Institute, vol. 73, no. partment, pp. 107-128, 2002.

[11] J. Y. Kim, H. J. Hwang, G. S. Ahn, J. C. Yoo, and J. H. Huh, “The establishment of the thermal performance standard of exterior windows in the extended balcony," Tech. Rep., House Research Institute, 2007.

[12] I. G. Lee, "Customizing remodeling items for deterioration apartment houses," House Research Institute Report, 2013.

[13] "Checklist of design criteria of building structures in consideration of remodeling," Ministry of Construction and Transportation Report, 2001.

[14] KICT, "Development of performance insurance system in construction new technology," KICT Report, 2007.

[15] KICT, "Study on strategy for development of apartment housing performance grade indication system," KICT Report, 2008.

[16] Y. K. Oh, "An assessment model for the indoor noise environment of aged apartment houses," Journal of Asian Architecture and Building Engineering, vol. 13, no. 2, pp. 445-451, 2014.

[17] G. S. Kim and S. Y. Jung, "Value evaluation using quantitative attribute in VE," Quality Innovation, vol. 2, no. 1, pp. 15-22, 2001.

[18] S. Y. Yoo and J. S. Yi, A Basic Study on the Application of QFD at Architectural Design Phase, Korea Institute of Construction Engineering and Management, 2005, Academic Annual Conference Proceedings.

[19] N. Singhaputtangkul, S. P. Low, A. L. Teo, and B.-G. Hwang, "Knowledge-based decision support system quality function deployment (KBDSS-QFD) tool for assessment of building envelopes," Automation in Construction, vol. 35, pp. 314-328, 2013.

[20] M. Li, L. Jin, and J. Wang, "A new MCDM method combining QFD with TOPSIS for knowledge management system selection from the user's perspective in intuitionistic fuzzy environment," Applied Soft Computing, vol. 21, pp. 28-37, 2014.

[21] J. A. Carnevalli and P. C. Miguel, "Review, analysis and classification of the literature on QFD-Types of research, difficulties and benefits," International Journal of Production Economics, vol. 114, no. 2, pp. 737-754, 2008.

[22] D. Ginn and M. Zairi, "Best practice QFD application: an internal/external benchmarking approach based on Ford Motors' experience," International Journal of Quality and Reliability Management, vol. 22, no. 1, pp. 38-58, 2005.

[23] J. S. Jeong, I. W. Ryoo, and Y. W. Lee, "A study on the choice of the curtain-wall type and the exterior material according to commercial building images by using the AHP," Architectural Society: Planning Section, vol. 22, no. 11, pp. 89-96, 2006.

[24] J. Lee and J. Chun, "Risk response analysis model for construction method using the forced-decision method and binary weighting analysis," Journal of Asian Architecture and Building Engineering, vol. 8, no. 1, pp. 205-212, 2009.

[25] J. S. Lee and J. Y. Chun, "Decision-making process for alternative selection of proper design change in construction project," Korean Journal of Construction Engineering and Management, vol. 11, no. 2, pp. 74-82, 2010.

[26] J. S. Lee and J. Y. Chun, "A numerical value evaluation model for the optimum design selection," Journal of Asian Architecture and Building Engineering, vol. 11, no. 2, pp. 283-290, 2012.

[27] K. M. Cho, "Evaluation of technologies ensuring green performance in multi-family housing projects in Korea," Journal of Asian Architecture and Building Engineering, vol. 13, no. 1, pp. 133-139, 2014.

[28] H. H. Lee, S. I. Kim, J. H. Lim, and S. Y. Song, "Case study of thermal insulation remodeling projects and analysis of restrictions," Architecture Institute of Korea Conference Proceedings, vol. 34, no. 1, pp. 231-232, 2014.

[29] H. Yin, P. Stack, and K. Menzel, "Decision support for building renovation strategies," in Proceedings of the ASCE International Workshop on Computing in Civil Engineering, pp. 834-841, June 2011.

[30] Y. Yau, "Multicriteria decision making for homeowners' participation in building maintenance," Journal of Urban Planning and Development, vol. 138, no. 2, pp. 110-120, 2012.

[31] H. Zhang and S. L. Lei, "An assessment framework for the renovation of existing residential buildings regarding environmental efficiency," Procedia-Social and Behavioral Sciences, vol. 68, pp. 549-563, 2012.

[32] C. L. Hwang and K. Yoon, Multiple Attribute Decision Making: Methods and Applications, vol. 186 of Lecture Notes in Economics and Mathematical Systems, Springer, Berlin, Germany, 1981.

[33] Qualitel, 2010, http://www.qualite-logement.org/accueil.html. 


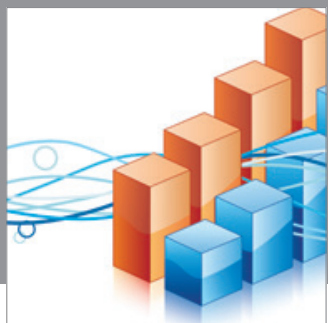

Advances in

Operations Research

mansans

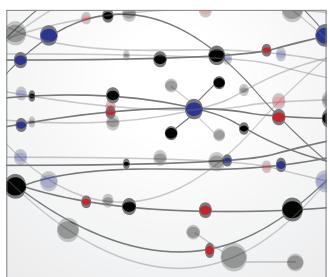

The Scientific World Journal
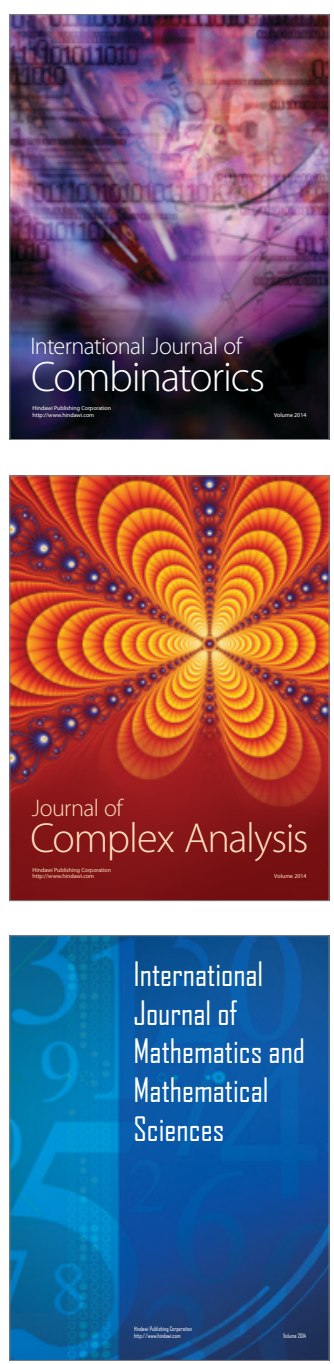
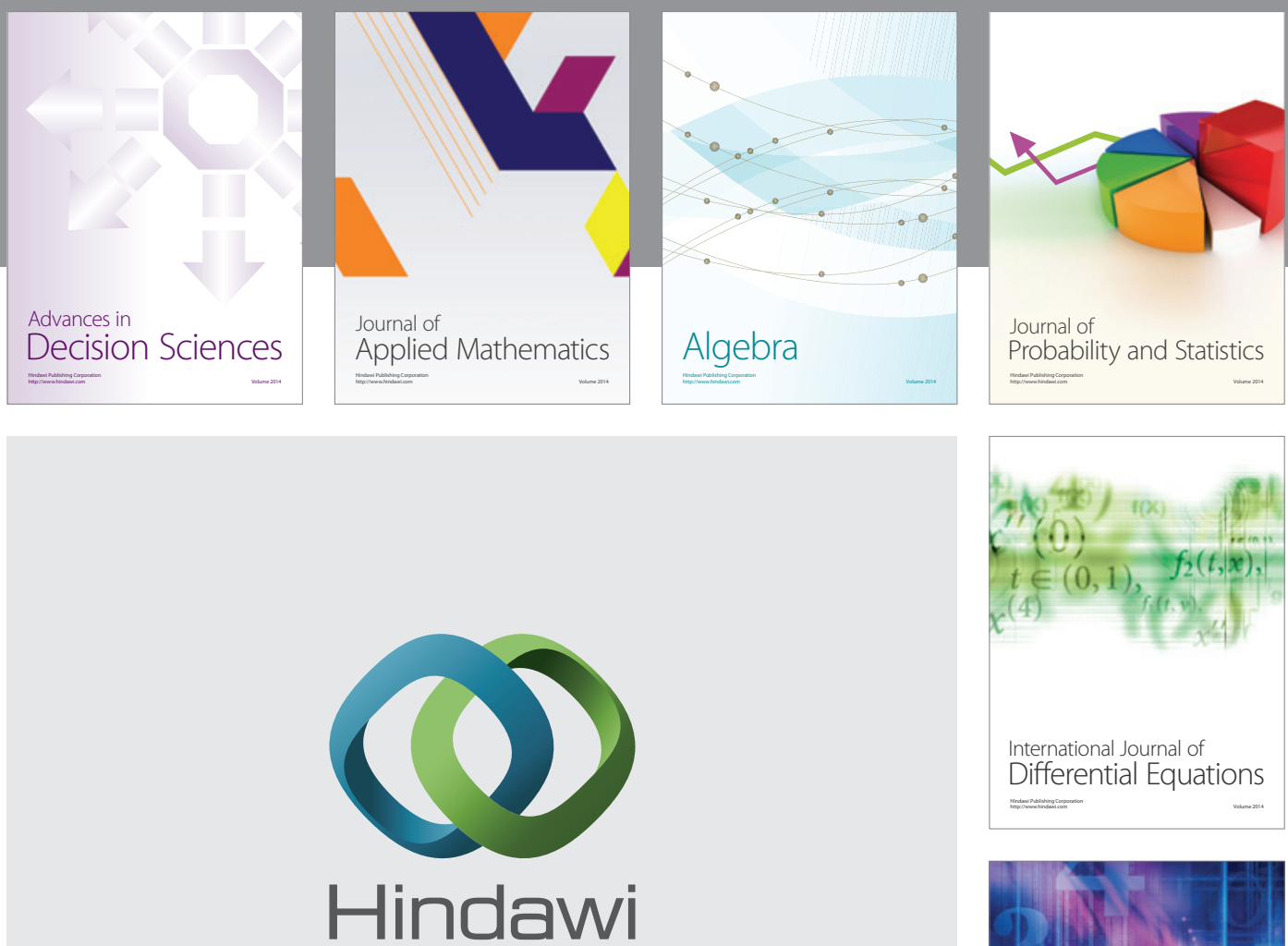

Submit your manuscripts at http://www.hindawi.com
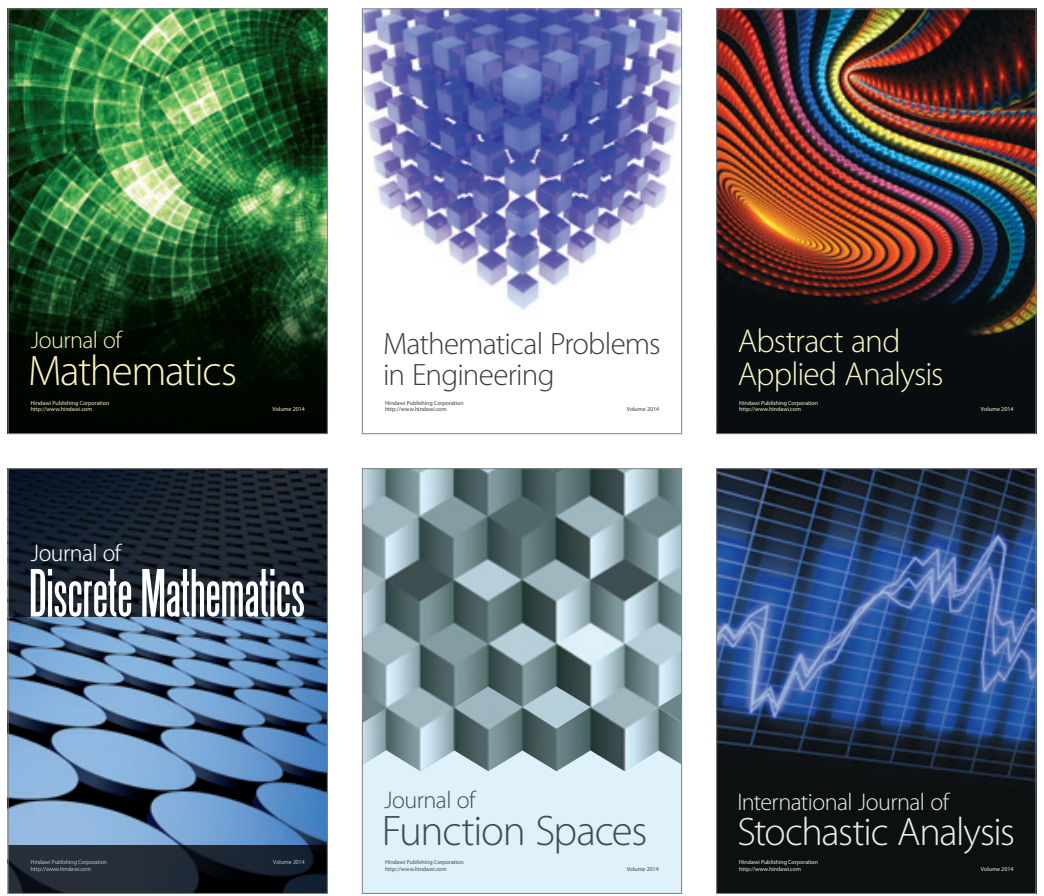

Journal of

Function Spaces

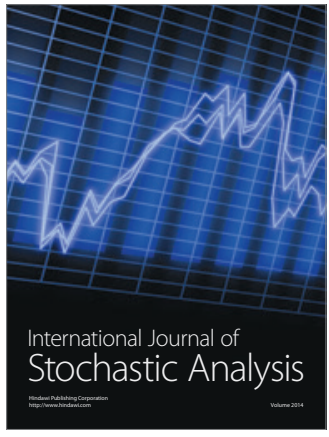

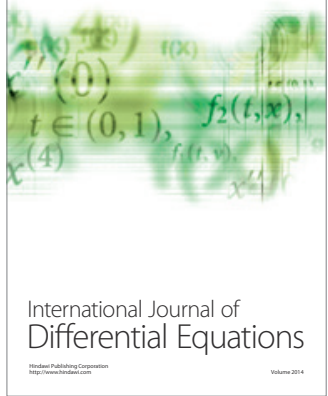
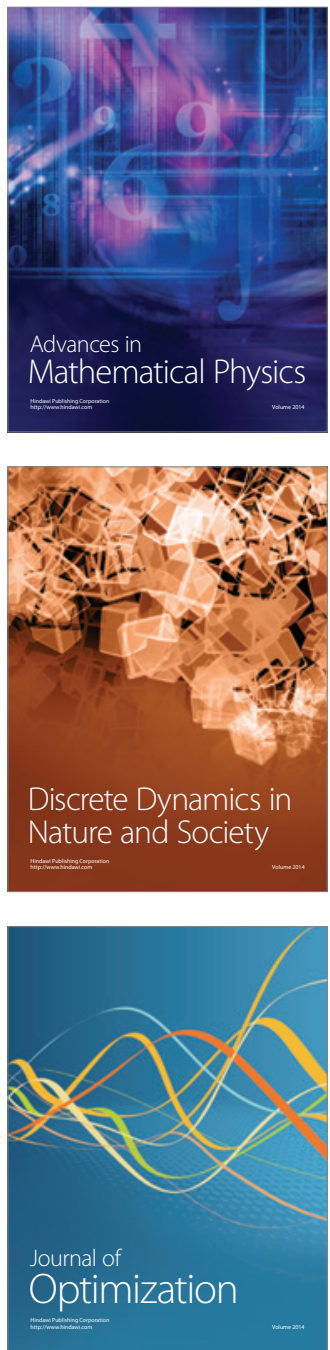